\title{
The technological acquisitions paradox in the beauty industry
}

\section{Technological acquisitions paradox}

\author{
Silvia Rita Sedita, Fiorenza Belussi and Ivan De Noni \\ Department of Economics and Management, University of Padova, Padova, Italy, and \\ Roberta Apa \\ Department of Environmental Science and Policy, University of Milan, Milan, Italy
}

\begin{abstract}
Purpose - We address the following research questions: (1) Is the innovation trajectory of the acquirer affected by previous acquisitions? (2) In which direction knowledge recombination from the acquisition is pushed further? (3) Is the technological acquisition more a means for knowledge exploration and radical innovation or, on the contrary, a way for consolidating previous technological specialization?

Design/methodology/approach - The nature of this study is exploratory; therefore, we opted for an inductive approach based on the L'Oréal case study analysis. Data were triangulated from different sources: (a) the L'Oréal website and press releases collected in the 2009-2015 period; (b) journal articles and books on the global cosmetics industry and the insightful work of Jones (2010); (c) the Questel Orbit database containing data on patents; and (d) the Zephyr - Bureau van Dijk database containing information on the acquisitions of firms. Findings - Empirical evidence from a patent data analysis reveals a paradoxical path. On the one hand, acquisitions enable the company to explore new technological spaces; on the other hand, they allow it to reinforce a preexisting technological trajectory, even when the knowledge base of the target is distant from that of the acquirer. Thus, in our case study, the absorption and recombination of knowledge from a variety of domains support specialization more than diversification technology strategies.
\end{abstract}

Originality/value - We add to innovation management literature a new perspective, by offering a detailed analysis, through patent data, of the knowledge recombination process, led by technological acquisitions.

Keywords Technological acquisitions, Knowledge acquisition and recombination, Specialization and diversification technology strategies, L'Oréal, Open innovation

Paper type Research paper

\section{Introduction}

Our work offers an original perspective of analysis on how technological acquisitions and knowledge recombination shape the innovation trajectories of the acquirer company. It does so by embracing an inductive research design, drawing on a single but very powerful case study, which analyses detailed acquisitions and patent data information of a market leader in the beauty industry, namely L'Oréal. As well put by Chiaroni et al. (2011), innovation research is often based on the observation of innovation strategies of high-tech companies, disregarding the wider portfolio of companies innovating in other industries, largely considered as low-tech. The beauty industry represents a peculiar and paradoxical case that illustrates the complexity of the knowledge recombination process, which deserves scientific attention from the innovation management scholars (Kumar et al., 2006).

Firms' innovation processes have been widely investigated from different perspectives. The current dominant paradigm is the open innovation model (Chesbourgh, 2003), which has come to constitute a new organizational imperative. The model has been implemented in a variety of ways. Some authors have focused on strategic alliances (Mowery et al., 1996; Doz,

(C) Silvia Rita Sedita, Fiorenza Belussi, Ivan De Noni and Roberta Apa. Published by Emerald Publishing Limited. This article is published under the Creative Commons Attribution (CC BY 4.0) licence. Anyone may reproduce, distribute, translate and create derivative works of this article (for both commercial and non-commercial purposes), subject to full attribution to the original publication and authors. The full terms of this licence may be seen at http://creativecommons.org/licences/by/4.0/legalcode 
EJIM

25,6

394

1996; Das and Teng, 2000; Dyer et al., 2001; Rosenkopf and Almeida, 2003; Grant and BadenFuller, 2004; Phelps, 2010), while others have studied the breadth and depth of collaborations aimed at innovation (Laursen and Salter, 2006). A small number of studies have highlighted the role of mergers and acquisitions (M\&As) in supporting the innovation activity of firms (Cloodt et al., 2006; Puranam and Srikanth, 2007; Grimpe and Hussinger, 2014; Sears and Hoetker, 2014; Orsi et al., 2015), still not precisely addressing the direction of their impact. Although the strategic use of acquisitions to acquire new knowledge and capabilities has become a well-institutionalized corporate phenomenon (Vermeulen and Barkema, 2001; Uhlenbruck et al., 2006), empirical evidence of how firms have recombined acquired knowledge remains scarce. However, it has been demonstrated that open innovation is more effective than closed innovation, and increases employees' performance (Alawamleh et al., 2018). Moreover, while several studies have focused on the role of technological relatedness in leveraging absorptive capacity during acquisitions (Ganzaroli et al., 2016), few have extended their interest to unrelated knowledge (Hagardon, 2003; Schoenmakers and Duysters, 2010) to explore the effect of this kind of knowledge acquisition on the specialization- or diversification-led technological orientation of the acquirer. We analyze these phenomena by defining knowledge as similar, complementary or unrelated to existing knowledge of the acquirer, in accordance with the technological classes in the patent portfolios of the acquiring firm and its target firms. By doing so, we add to innovation management literature by offering a detailed analysis, through patent data, of the knowledge recombination process led by technological acquisitions. In particular, we address the following research questions: (1) Is the innovation trajectory of the acquirer affected by previous acquisitions? (2) In which direction knowledge recombination from acquisition is pushed further? (3) Is the technological acquisition more a mean for knowledge exploration and radical innovation or, on the contrary, a way for consolidating previous technological specialization?

In order to answer the research questions, our work identifies various ways of using the target's knowledge and the different forms of recombination that can affect the technological patterns of knowledge accumulation and growth (Antonelli et al., 2010; Gruber et al., 2013). Technological acquisitions enable acquiring companies to access the target's knowledge, which may be related (similar or complementary) or unrelated to the knowledge of the acquirer. After the acquisition, the acquirer's capacity to exploit this external knowledge (acquired knowledge) depends on the ability of the acquirer to recombine new and owned knowledge to realize novel technological combinations, or to refine known combinations for new uses and applications - developed knowledge (Kogut and Zander, 1992; Carnabuci and Operti, 2013). By matching the characteristics of acquired knowledge and developed knowledge, we can identify how a technological acquisition affects the technological trajectory of the acquirer.

Specifically, thanks to the findings coming from the L'Oréal case study analysis, we have identified and contrasted two possible post-acquisition technological trajectories: specialization and diversification. An acquirer that follows a trajectory of specialization seeks to innovate in its core technology class or in classes with similar technological principles. Conversely, an acquirer following a trajectory of diversification seeks to innovate in new technology classes that are far from its existing knowledge domain. The capacity to balance diverse kinds of acquired and developed knowledge might be the result of ambidexterity or a punctuated equilibrium strategy (Gupta et al., 2006), and might affect both the breadth and the depth of the acquirer's technological portfolio. From this perspective, acquired and developed knowledge respectively represent the input and the output of the recombinant process involved in the technological acquisitions (Hitt et al., 1998).

Data were triangulated from a variety of sources, including press releases, journal articles, books and database records on patents and acquisitions. The paper is structured as follows. Section two presents the theoretical background. Section three explains the methodology. 
Section four presents our major findings, which are further discussed in section five. Finally, section six summarizes our main contribution, the implications for theory and practice, and, as usual, limitations and directions for future research.

\section{Theoretical background}

The speed of technological innovation and the rapid technology obsolescence in high-tech environments has forced innovative companies to shorten the time they spend on research and development (R\&D) and to reduce risks while keeping their competitive advantages (Tsai et al., 2018). To be innovators or fast followers in dynamic and highly competitive technological markets, organizations must balance their internal R\&D capabilities with external knowledge (Schildt et al., 2005), which they can acquire through collaborations, strategic alliances, joint ventures and acquisitions (Ahuja and Katila, 2001).

Technological takeovers have specific advantages that do not apply to other acquisition modes, since they enable companies to acquire external and consolidated technological inputs quickly, and focus their internal resources and capabilities on recombining acquired knowledge, instead of developing new knowledge ex novo, thereby hastening innovation performance, and reducing the time to market. Several studies have shown that a firm's recombination capabilities mainly depend on its absorptive capacity (Cohen and Levinthal, 1990). Zahra and George (2002) distinguished between potential and realized absorptive capacity. Whereas the former involves acquisition and assimilation, the latter focuses on transformation and exploitation. Todorova and Durisin (2007) stressed the iterative links between assimilation, transformation and exploitation. More recently, Patterson and Ambrosini (2015) reconceptualized absorptive capacity for research-intensive firms by focusing on the iterative nature of the assimilation process, which must be developed during, rather than solely after, the acquisition process, and should be continually adjusted throughout the transformation and exploitation phases. These contributions indicate that acquisition and assimilation are necessary but not sufficient conditions for innovation, because they must be complemented by recombinant capabilities (Carnabuci and Operti, 2013; Verhoeven et al., 2016; Nagle and Teodoridis, 2020). On this point, Deng (2010) argued that some firms can acquire and assimilate new external knowledge from targets but may fail to transform and exploit it successfully. Similarly, Vasudeva and Anand (2011) and Orsi et al. (2015) focused on knowledge utilization, measuring the extent to which acquirers can use external acquired knowledge to generate innovations.

The importance of existing complementarities between the acquired and the target knowledge bases has been widely emphasized in more recent studies on acquisition processes (Rothaermel and Boeker, 2008; Junni et al., 2015; Makri et al., 2010; Zaheer et al., 2013; Bauer and Matzler, 2014). M\&As provide opportunities for firms to complement and renew their knowledge base (Bresman et al., 1999). Thus, knowledge acquisition and knowledge recombination, which involves the exploitation and exploration of internal and external knowledge flows, enable firms to expand their knowledge base by capitalizing on opportunities for both incremental and radical innovation (Chesbrough, 2003; Love and Roper, 2009; Lichtenthaler, 2009). Similarly, Makri et al. (2010) highlighted that technological similarity supports incremental processes of innovation while complementary acquisitions lead to discontinuous strategic transformations.

Access to external knowledge sources, combined with internal R\&D, might boost a more creative recombination process (Rothaermel and Alexandre, 2009; Lin and Wu, 2010), conducive to explorative rather than exploitative innovation performance (Lavie et al., 2010; Ganzaroli et al., 2016). From this perspective, multiple technological acquisitions can enable companies to develop an ambidexterity strategy to support exploitative and explorative performance by combining technologically differentiated types of knowledge. A repeated
Technological acquisitions paradox 
EJIM

25,6

acquisitions strategy provides opportunities for learning (Öberg, 2011) and establishes a routine of exploration, enabling firms to explore "adjacent possible" trajectories (Kauffman, 2000). Such a strategy is conducive to the development of novelties and innovations. The benefits of multiple technological acquisitions depend on a firm's capacity to recombine similar, complementary or even unrelated external knowledge. This can extend the breadth and depth of the firm's technological domains (Katila and Ahuja, 2002). In contrast, this process might involve a trade-off between external technology acquisition and internal R\&D expenditure when available resources are limited (Kang et al., 2015).

\section{Method}

Based on the theory of technological acquisitions and knowledge recombination, our work aims at answering three original research questions: (1) Is the innovation trajectory of the acquirer affected by previous acquisitions? (2) In which direction knowledge recombination from acquisition is pushed further? (3) Is the technological acquisition more a mean for knowledge exploration and radical innovation or, on the contrary, a way for consolidating previous technological specialization?

Because the area of investigation is relatively novel, the nature of this study is exploratory; therefore, an inductive approach is appropriate. We focus on the collection of rich quantitative and qualitative data through case study research (Yin, 2003). We do not test hypotheses statistically, but instead, we aim to offer some useful propositions, which we discuss in light of theory and that can be further tested using a deductive approach (Eisenhardt, 1989). In particular, this research uses a single case study design to provide an indepth analysis of a real-world case (Yin, 1981, 2014; Eisenhardt, 1989). As suggested by Siggelkow (2007, p. 22), "research involving case data can usually get much closer to theoretical constructs and provide a much more persuasive argument about causal forces than broad empirical research can". The benefits of a case study approach include the ability to combine a broad knowledge of the context with a higher level of detail, supporting a more in-depth understanding of the innovation process in the context of an acquisition strategy. Evidently, focusing on a single case study limits the generalization of results. However, it inspires some interesting propositions able to positively feed the debate concerning the interplay between technological acquisitions and knowledge recombination process. This case study focuses on L'Oréal[1], a large company operating within the beauty industry. This company was chosen for two main reasons. First, L'Oréal is a particularly innovative company, which invests approximately $3 \%$ of its yearly sales revenue in internal R\&D (Belussi et al., 2016) and has an impressive patenting record. L'Oréal's portfolio currently includes more than 14,000 patents in 289 four-digit (and 1,372 seven-digit) technological classes (according to our search in the Orbit database). Second, in its history, L'Oréal has carried out many acquisitions, which indicates a strong external growth strategy.

Following Mathison (1988), we aimed to improve the reliability and validity of our research findings through data triangulation. Data were triangulated from different sources. First, qualitative data were retrieved from the L'Oréal website and press releases collected in the 2009-2015 period, as well as journal articles and books on the global cosmetics industry and the insightful work of Jones (2010), in order to explore the L'Oréal's acquisition strategy and to better classify "technological" acquisitions with respect to "strategic" acquisitions. Then, quantitative data were collected from Zephyr - Bureau van Dijk database, which provided information about acquired targets, and Questel Orbit database, which provided data on L'Oréal and acquired targets' patent portfolios.

Preliminarily, we started by mapping L'Oréal's acquisitions from 1928 (the year of the company's first acquisition) to 2015. We retrieved this information from the Zephir - Bureau van Dijk database. We counted 52 acquisitions and classified these as either "technological" 
or "strategic," following a widely accepted conceptualization based on two criteria (Ziedonis, 2004; Hung and Tang, 2008; McCarthy and Aalbers, 2016). First, a technological acquisition is defined as involving a target firm that exhibits patenting activity. Where the acquired target continued to operate independently after the acquisition, we also consider its patenting activity after the acquisition. Second, the patents of the acquired firm should be cited in the patent documents filed by the acquiring firm after the acquisition. Patents that are coassigned to both target and acquirer are excluded, since they are derived from cooperative research activity. Therefore, we analyzed the 14 technological acquisitions in which the target firm had at least one patent cited by L'Oréal after its acquisition. Additionally, we controlled for information collected throughout qualitative data in order to ensure the technological motivation of acquisition.

Then, we followed a three-step empirical strategy, as shown in Figure 1, whereby we first identified the characteristics of what we labeled acquired knowledge (first step). Second, we identified the characteristics of what we labeled developed knowledge (second step). Finally, we assessed the degree to which the acquired knowledge matched the developed knowledge, which informed us about the technological trajectory of the firm after its acquisitions (third step).

Operationally, in the first step, we collected all patents of targets cited by L'Oréal after an acquisition, and then compared the technological classes of the cited patents with those of L'Oréal before the date of acquisition (depending on the target). This enabled us to measure the distance between existing and acquired knowledge according to the technological classes, and in turn to identify the characteristics of the acquired knowledge. Technological classes were defined according to the International Patent Classification (IPC) provided by the World Intellectual Property Organization (WIPO). In so doing, we distinguished between similar, complementary and unrelated knowledge. Acquired knowledge was classified as similar when its technological class was detected in L'Oréal patents portfolio at the seven-digit IPC level. It was considered complementary if it was only detected in the L'Oréal patent portfolio at the four-digit IPC level. Finally, it was considered unrelated if it was completely new to the L'Oréal portfolio of technologies [2].

In the second step, we primarily collected all citing patents (patents filed by L'Oréal that cited targets), in order to compare the technological classes of the citing patents (at the four-
Technological acquisitions paradox

397

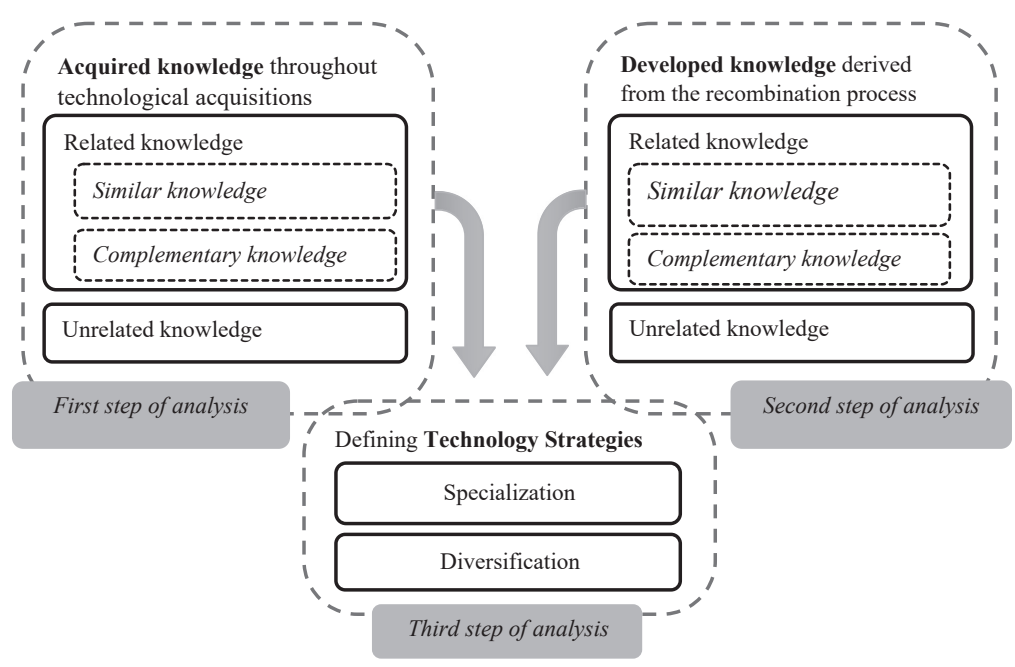

Figure 1. Analytical framework matching acquired and developed knowledge to define the technological trajectory after acquisition: A threestep empirical strategy 
EJIM

25,6

\section{8}

and seven-digit IPC level) to the existing technological classes of L'Oréal's portfolio until one year before the priority date. Adopting the same methodology discussed above, we distinguished between similar, complementary and unrelated developed knowledge.

Finally, this enabled us to compare acquired and developed knowledge and to assess (in the third step) whether the L'Oréal's technological trajectory was oriented more toward specialization or diversification.

\section{Results}

\subsection{Characteristics of L'Oréal's patent portfolio}

To deepen our understanding of L'Oréal's technological trajectory, and evaluate how it has been affected by technological acquisitions, we mapped the characteristics of L'Oréal's patent portfolio, focusing on the technological classes of the patents. The graph in Figure 2 shows the technological classes reported in the patent portfolio (each year reports the cumulated number of technological classes within a ten-year window). The distribution of the technological classes at the four-digit IPC level is represented in light grey, while the distribution at seven-digit IPC level is presented in dark grey. Figure 2 informs of the existence of two periods. The first period (1970-2010) shows exponential growth in the number of technological classes, suggesting a tendency toward knowledge diversification, while in the second period (2011 onward), a clear pattern of specialization emerges.

\subsection{The characteristics of acquired knowledge}

To assess the impact of different types of acquired knowledge on the technological trajectory of L'Oréal, we first needed to classify the acquired knowledge (first step in Figure 1). L'Oréal's acquired knowledge is embodied in 91 patents that were exclusively owned by the target and cited by L'Oréal after the acquisition. Knowledge acquired from external sources through

Figure 2.

The evolution of L'Oréal's technological portfolio: Distribution of technological classes per year (10-year mobile window)

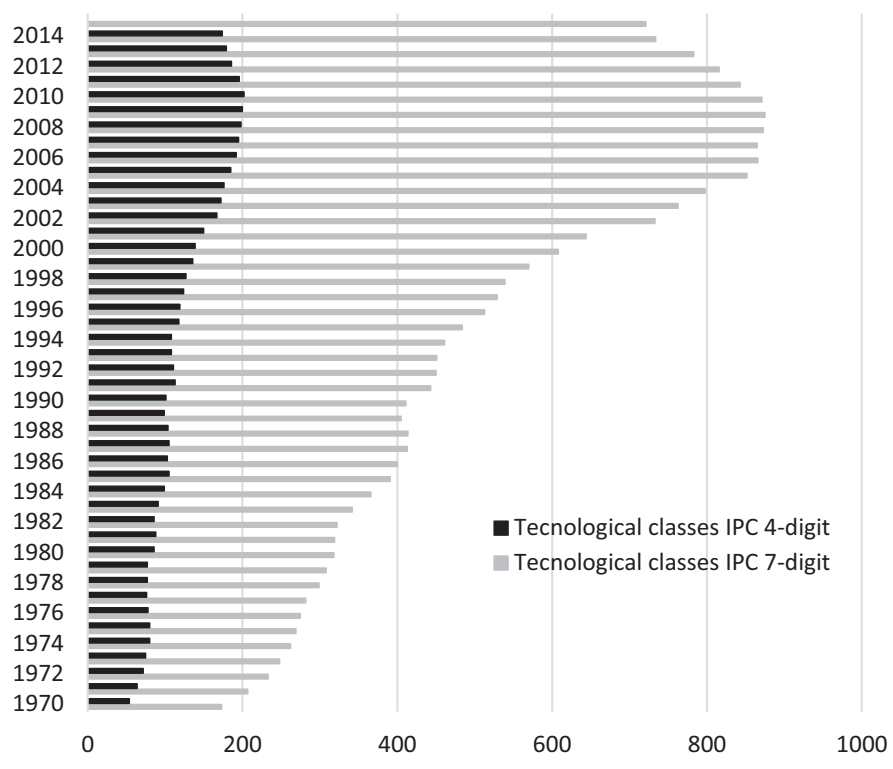


acquisitions accounted for less than $4 \%$ of L'Oréal's invention activity up to 2015, indicating acquisitions had only a minor impact on the innovation performance of the company.

We identified the technological fields to which the patents referred at both the four-and seven-digit IPC level and found that the acquired patents covered 137 technological classes at the seven-digit level and 33 at the four-digit level. We examined the technological classes of the 91 patents of the targets to explore the degree of technological similarity between the acquired knowledge and L'Oréal existing knowledge base before the acquisitions. Operationally, the technological classes (at both the four- and seven-digit levels) of each target patent were compared to the technological classes of L'Oréal patent portfolio before the acquisition to establish whether the acquired knowledge was similar, complementary or unrelated (Table 1).

The data in Table 1 reveal the following important findings.

(1) Technological acquisitions are based largely on knowledge similarity rather than complementarity or unrelatedness. Table 1 shows that through its acquisitions, L'Oréal mainly acquired knowledge that was similar to its existing knowledge. Of the 137 technological classes associated with the 91 patents from 14 acquisitions, 94 were found in L'Oréal's existing patent portfolio at the seven-digit level, representing similar knowledge; 43 were found at the four-digit level, representing complementary knowledge; and only 11 classes were new to the portfolio, representing unrelated knowledge.

(2) The company's acquisition strategy appears to have developed in two main phases. In the earlier phase, up to 1996, L'Oréal may have followed a polarized search strategy. In this period, it extended the depth of its knowledge portfolio by mainly
Technological acquisitions paradox

399

\begin{tabular}{|c|c|c|c|c|c|c|}
\hline \multirow[b]{2}{*}{ Target } & \multirow[b]{2}{*}{$\begin{array}{c}\text { Year of } \\
\text { acquisition }\end{array}$} & \multicolumn{2}{|c|}{ Targets' patents } & \multicolumn{3}{|c|}{ Acquired knowledge } \\
\hline & & $\begin{array}{l}\text { \# Cited } \\
\text { patents }\end{array}$ & $\begin{array}{l}\text { \# Tech. } \\
\text { classes }\end{array}$ & Similar & Complementary & Unrelated \\
\hline BIOTHERM & 1970 & 2 & 9 & 6 & 1 & 2 \\
\hline $\begin{array}{l}\text { SANOFI/ } \\
\text { SYNTHÉLABO }\end{array}$ & 1973 & 23 & 75 & 32 & 36 & 7 \\
\hline $\begin{array}{l}\text { HELENA } \\
\text { RUBINSTEIN }\end{array}$ & 1984 & 2 & 7 & 7 & 0 & 0 \\
\hline MENNEN & 1988 & 19 & 21 & 17 & 3 & 1 \\
\hline ROCHE POSAY & 1988 & 4 & 22 & 22 & 0 & 0 \\
\hline DELALANDE & 1991 & 2 & 20 & 16 & 4 & 0 \\
\hline MAYBELLINE & 1996 & 18 & 23 & 22 & 1 & 0 \\
\hline SOFT SHEEN & 1998 & 6 & 2 & 2 & 0 & 0 \\
\hline $\begin{array}{l}\text { CARSON } \\
\text { PRODUCT }\end{array}$ & 1998 & 5 & 7 & 7 & 0 & 0 \\
\hline UEMURA & 2000 & 2 & 5 & 5 & 0 & 0 \\
\hline SKINCEUTICAL & 2005 & 1 & 6 & 6 & 0 & 0 \\
\hline The BODY SHOP & 2006 & 3 & 5 & 5 & 0 & 0 \\
\hline YSL BEAUTE & 2008 & 1 & 11 & 11 & 0 & 0 \\
\hline COLORIGHT & 2014 & 3 & 13 & 12 & 0 & 1 \\
\hline TOTAL & & 91 & 137 & 94 & 43 & 11 \\
\hline
\end{tabular}

Note(s): The sum of technological classes covered by the patents of the acquired firms (at the seven-digit level) is larger than 137 , since a patent can refer to different technologies and the same technology might be included in different patents. Moreover, the same acquired technologies, which are unrelated in a given acquisition, might be classified as similar or related in successive acquisitions when they are effectively used to expand the breadth of L'Oréal's technological portfolio. This explains why the sum of similar, complementary and unrelated technologies is not equal to the total

Table 1.

Characteristics of the acquired knowledge 
EJIM

25,6

400

tapping into similar knowledge but also exploring unrelated knowledge. In the second period, the search strategy focused solely on similar knowledge, except for its takeover of Coloright. The company's takeover of Coloright represents the only exception. In the first phase, L'Oréal acquired important large and diverse targets, such as Sanofi, Mennen and Maybelline, which enabled it to access differentiated knowledge bases, some of which were related and some unrelated to its existing knowledge, in the search for breakthrough innovations. In the second phase, the acquisition strategy appears to be oriented toward the acquisition of more specialized targets. This mirrors a clear-cut research process, focused on improving existing technologies rather than discovering new technological trajectories.

\subsection{The characteristics of developed knowledge}

To connect the acquired knowledge to the company's technological trajectory, we had to identify the nature of the developed knowledge (second step in Figure 1). The developed knowledge is embodied in 466 citing patents of the acquiring firm. L'Oréal's citing patents covered 170 technological classes at the seven-digit level and 48 classes at the four-digit level. As explained in the methodology session, the characteristics of the developed knowledge can inform us whether L'Oréal's innovation trajectory was one of specialization or diversification. By studying the developed knowledge, we can gain insights into the recombination capabilities of the company, which leverages knowledge acquired by the targets and recombines this with its accumulated preexisting knowledge to develop an innovation strategy based on the creation of new technologies.

The data in Table 2 reveal the following important findings.

(1) L'Oréal's exploitation and recombination processes were primarily oriented toward increasing the specialization of the company's technological trajectory. Most of L'Oréal's patents that cite acquired knowledge from targets relate to technological classes already associated with its patent portfolio, indicating a path-dependent technological trajectory.

(2) We can observe two main phases. In the first phase, before 1998, acquired knowledge only occasionally contributed to the process of diversification. The findings show that only in about $5 \%$ of the cases was acquired knowledge effectively used to develop complementary $(4.15 \%)$ and unrelated $(1.28 \%)$ technological trajectories. In the second phase, after 1998, the trajectory is largely one of specialization.

\subsection{Comparing acquired and developed knowledge}

The similar distribution of data in Tables 1 and 2 suggests a potential correlation between the activities of exploration and assimilation and those of exploitation and recombination. A cross-tabulation analysis enables us to assess how different forms of acquired knowledge affected the development of technological specialization or diversification (third step in Figure 1).

The analysis reveals that L'Oréal mainly used the external knowledge it acquired from technological acquisitions to intensify the specialization of its own knowledge base. Table 3 shows that the knowledge recombination process involved mainly acquired knowledge that was similar to the company's existing knowledge and was used to develop knowledge that was also similar ( $82.13 \%$ of cases). Column conditional percentages (the first value in brackets) disclose that different types of developed knowledge mainly rely on similar acquired knowledge (similar acquired knowledge affects the $82.7 \%$ of similar, $73.21 \%$ of complementary and $69.56 \%$ of unrelated developed knowledge). Row conditional percentages further stress that different types of acquired knowledge mainly affect a 


\begin{tabular}{|c|c|c|c|c|c|c|}
\hline \multirow[b]{2}{*}{ Target } & \multirow[b]{2}{*}{$\begin{array}{c}\text { Year of } \\
\text { acquisition }\end{array}$} & \multicolumn{2}{|c|}{ L'Oréal citing patents } & \multicolumn{3}{|c|}{ Developed knowledge } \\
\hline & & $\begin{array}{l}\text { \# Citing } \\
\text { patents }\end{array}$ & $\begin{array}{l}\text { \# Tech. } \\
\text { classes }\end{array}$ & Similar & Complementary & Unrelated \\
\hline BIOTHERM & 1970 & 6 & 14 & 14 & 0 & 0 \\
\hline $\begin{array}{l}\text { SANOFI/ } \\
\text { SYNTHÉLABO }\end{array}$ & 1973 & 39 & 69 & 65 & 3 & 1 \\
\hline $\begin{array}{l}\text { HELENA } \\
\text { RUBINSTEIN }\end{array}$ & 1984 & 3 & 7 & 7 & 0 & 0 \\
\hline MENNEN & 1988 & 222 & 82 & 75 & 4 & 3 \\
\hline ROCHE POSAY & 1988 & 10 & 25 & 23 & 2 & 0 \\
\hline DELALANDE & 1991 & 3 & 11 & 11 & 0 & 0 \\
\hline MAYBELLINE & 1996 & 149 & 63 & 60 & 3 & 0 \\
\hline SOFT SHEEN & 1998 & 29 & 14 & 13 & 1 & 0 \\
\hline $\begin{array}{l}\text { CARSON } \\
\text { PRODUCT }\end{array}$ & 1998 & 34 & 7 & 7 & 0 & 0 \\
\hline UEMURA & 2000 & 2 & 6 & 6 & 0 & 0 \\
\hline SKINCEUTICAL & 2005 & 1 & 6 & 6 & 0 & 0 \\
\hline The BODY SHOP & 2006 & 3 & 4 & 4 & 0 & 0 \\
\hline YSL BEAUTE & 2008 & 1 & 2 & 2 & 0 & 0 \\
\hline COLORIGHT & 2014 & 2 & 3 & 3 & 0 & 0 \\
\hline TOTAL & & 466 & 170 & 153 & 13 & 4 \\
\hline
\end{tabular}

Technological acquisitions paradox

Table 2.

Characteristics of the developed knowledge

\begin{tabular}{|c|c|c|c|c|c|}
\hline \multirow{2}{*}{\multicolumn{2}{|c|}{ Acquired knowledge }} & \multicolumn{3}{|c|}{$\begin{array}{l}\text { Developed knowledge } \\
\text { Related }\end{array}$} & \multirow{6}{*}{$\begin{array}{r}\text { Table } 3 . \\
\text { Cross-tabulation table } \\
\text { comparing acquired } \\
\text { and developed } \\
\text { knowledge }\end{array}$} \\
\hline & & Similar & Complementary & Unrelated & \\
\hline \multirow{3}{*}{$\begin{array}{l}\text { Related } \\
\text { Unrelate }\end{array}$} & Similar & $82.13 \%(82.70 \% ; 99.41 \%)$ & $0.33 \%(73.21 \% ; 0.40 \%)$ & $0.16 \%(68.56 \% ; 0.19 \%)$ & \\
\hline & Complementary & $14.77 \%(14.88 \% ; 98.67 \%)$ & $0.12 \%(26.94 \% ; 0.79 \%)$ & $0.08 \%(31.44 \% ; 0.56 \%)$ & \\
\hline & & $2.40 \%(2.42 \% ; 100 \%)$ & $O \%(0 \% ; 0 \%)$ & $0 \%(0 \% ; 0 \%)$ & \\
\hline \multicolumn{5}{|c|}{ Note(s): Values in brackets represent column and row conditional percentages respectively } & \\
\hline
\end{tabular}

similar knowledge development process (similar, complementary and unrelated acquired knowledge respectively determine the $99.41 \%, 98.67 \%$ and $100 \%$ of similar developed knowledge).

The second-most prominent pattern represents the use of complementary knowledge from the target to develop mainly similar knowledge (similar to the company's existing knowledge) $-14.77 \%$ of the cases. The last pattern observed shows the use of unrelated knowledge from the target to develop similar knowledge (similar to the company's existing knowledge) $2.4 \%$ of the cases. In other words, L'Oréal uses most of the similar, complementary and unrelated knowledge it acquired to support a path-dependent innovation trajectory that reinforced its technological specialization. Only in a few cases did L'Oréal develop pathbreaking knowledge from technological acquisitions, and this occurred more often when it recombined similar or complementary technologies rather than unrelated ones.

For a clearer understanding of L'Oréal's acquisition and recombination process and to support the evidence presented so far, we provide some empirical examples, which we subject to a more fine-grained analysis.

(1) The first case considered is the acquisition of Biotherm in 1970. Biotherm owned some unrelated knowledge that was exploited by L'Oréal through an effective 
EJIM

25,6

402

recombination process, which increased the specialization of L'Oréal's patent portfolio. After the acquisition, Biotherm continued to operate independently, and in 1976, it was granted a patent (family ID US4187291) that referred to the technological classes A61P-003 (drugs for disorders of the metabolism) and A61P-029 (non-central analgesic, antipyretic or anti-inflammatory agents, such as antirheumatic agents and non-steroidal anti-inflammatory drugs), which were new to the L'Oréal knowledge domain. Interestingly, L'Oréal only used that knowledge effectively in 1990, when it was granted a patent (family ID 3921276) citing Biotherm's invention. L'Oréal's patent exploited Biotherm's unrelated knowledge on the cosmetic composition of a skin treatment with an anti-inflammatory or anti-edematous agent to aid slimming and prevent cellulite. This innovation constituted an incremental step in L'Oréal's technological portfolio rather than a new direction. In summary, even though the takeover led to the acquisition of unrelated knowledge, this knowledge was exploited to increase the specialization rather than the diversification of the company's technological portfolio.

(2) The second example concerns the exploitation of knowledge acquired from Mennen in 1988. As a result of this takeover, L'Oréal recombined some unrelated knowledge from Mennen concerning a container with a roller element to dispense liquid (Mennen's patent US3095598 of 1960, referring to the technology class B43M-011) with its existing knowledge domain in another incremental step on its innovation path. This knowledge was used by L'Oréal to devise a new container/applicator comprising a reservoir for the product and an applicator (L'Oréal's patent 24913 in 2000), a technology that is useful for the application of "liquid powders" and that, therefore, relates to the company's traditional fields of makeup and skincare.

(3) The third case considered is the takeover of Sanofi-Synthelabo by L'Oréal in 1998. In this case, the unrelated knowledge acquired through the acquisition was used to enhance L'Oréal's traditional technological patent portfolio, which was largely based on technologies related to beauty treatments. L'Oréal used an original SanofiSynthelabo patent filed in 1998 (family ID US6767533), which referred to the technological class $\mathrm{C} 12 \mathrm{~N}-001$ (concerning the process of preparing compounds or compositions using microorganisms or enzymes), for the preparation of skin treatments. The patent specifically described a composition containing a peripheral benzodiazepine receptor ligand for topical use to treat cutaneous stress. L'Oréal's citing patent (family ID 14346750), which was registered in 2004, applied this new technology to create a medicament (or dietary agent) for oral administration, which contained blueberry extract, antioxidants and micronutrients to benefit the skin. This opened up a technological new field, nutritive cosmetics and several breakthrough innovations in the beauty sector, related to pills to improve skin and hair. However, these radical innovations were part of a consolidated specialization pattern.

(4) More recently, in 2014, L'Oréal exploited unrelated knowledge with its takeover of Coloright. We specifically refer to patent 44664471, which is for a dispenser for a composition to treat keratinous fibers (registered in the technological class B01B-001, concerning boiling apparatuses for physical or chemical purposes). L'Oréal used this technology to develop a system for dispensing makeup and hair coloring appliance (see L'Oréal's patents 73234887 and 73093016 of 2014), which was linked to its existing technological core.

(5) With the technological acquisition of Synthelabo in 1973, L'Oréal was able to access a large amount of external knowledge. Although most of this knowledge was similar to 
L'Oréal's existing knowledge, some of Synthelabo's patents included some unrelated knowledge, such as a patent registered in 1975 (family ID 165629) for a new technology (A61P-025 referring to drugs for disorders of the nervous system) within the class A61P (specific therapeutic activity of chemical compounds or medicinal preparations). An analysis of the two L'Oréal patents filed in 1989 (family IDs 12977479 and 62266232) in which Synthelabo's patent was cited indicates that L'Oréal mainly used this new technology within its core specialization to develop thickening agents for its products in the cosmetic field, particular for lipsticks, nail varnishes and creams. However, these thickening agents could also be used in other unrelated fields, such as liquid carbonaceous fuels (C10L-001). This enabled L'Oréal to protect its inventions in many technological fields.

(6) Another example is a Mennen patent (family ID 59971699) cited by L'Oréal in 1997. The invention was a cosmetic composition containing the thickening agent siloxane polymer. In 2004, L'Oréal filed a patent (family ID 968564) in which this component was used in compositions containing keratin and keratinous materials. Again, this strengthened L'Oréal's core knowledge base.

\section{Discussion}

This article comprises a historical analysis of L'Oréal's innovation strategy in relation to its significant technological acquisitions. The first finding concerns the extent to which this leading global firm, during the last four decades, based its innovation activity on a model of closed innovation. In fact, of its intensive knowledge production, covering (more than) 14,000 EU patents registered by L'Oréal (Orbit database, 1928-2015), only a small portion is from the recombination of external knowledge deriving from takeovers. Only 14 of L'Oréal's 52 acquisitions were related to technology. Thus, external acquisition of knowledge appears to have played a marginal role (only 91 patents of L'Oréal's patents cited targets that the company had acquired) in the company's innovation strategy, with developed knowledge derived from the recombination process accounting for less than $4 \%$ of its cumulative inventing activity. The case of L'Oréal presents a challenge to the imperative of open innovation and shows the effectiveness of the old internal model of innovation. The evidence we collected enabled us to trace L'Oréal's technological trajectories, which indicate an internal linear model of knowledge accumulation studded by a small sequence of technological acquisitions of companies that generally owned knowledge that was similar to L'Oréal's existing knowledge.

In particular, our findings confirm that the absorption of similar and complementary knowledge is conducive to an innovation trajectory that strengthens the firm's technological specialization. The acquisition of similar knowledge is less costly for an organization and better supports the transformation of acquired knowledge into exploitable knowledge (Deng, 2010). Firms more easily recognize and absorb external knowledge close to their existing knowledge base (Cohen and Levinthal, 1990), because they can easily spot its potential. Consequently, acquisition strategies are more often directed toward firms operating in close knowledge domains, where the result of knowledge recombination is more predictable, making the acquisition less risky. However, the closeness between the acquirer's and the target's knowledge bases and the technological overlap limits the innovative output (Nooteboom et al., 2007). Similarly, technological proximity reduces the acquirer's opportunities for learning (Hitt et al., 1996), resulting in an incremental rather than a radical innovation process. Thus, it has been claimed that the development of radical innovations might depend more on access to knowledge from different scientific domains and knowledge sources, on the condition that the distance is not 
EJIM

25,6

too large (Colombo and Rabbiosi, 2014; Cassiman and Veugelers, 2006; Sears and Hoetker, 2014). This aligns with recent studies on regional innovation policies, which have found technological relatedness to be a critical driver of technological development and progress (Boschma, 2017; Apa et al. 2018; Balland et al., 2019). Makri et al. (2010) argued that related knowledge can include not only similar knowledge but also complementary knowledge, both of which can contribute to a specialization path (Ganzaroli et al., 2016). Therefore, Proposition 1 is derived.

Proposition 1. Technological acquisitions enable companies to increase their technological specialization through a recombination process that exploits similar or complementary knowledge from the target.

When the technological distance is significant, the invention process may be more complex and costly (Nooteboom et al., 2007). Nevertheless, several studies have highlighted that technological unrelatedness can trigger more radical forms of invention (Phene et al., 2006; Frenken et al., 2007; Castaldi et al., 2015). In such cases, external knowledge acquisition can increase a firm's ability to profit from path-breaking (Nagle and Teodoridis, 2020). This finds theoretical justification in the Schumpeter's idea (1911) that radical path-breaking innovations result from novel combinations of knowledge. However, unrelated knowledge combinations remain unexplored as sources for new path development and structural change (Grillittsch et al., 2018; Miller et al., 2007). Often, the process of creating radical breakthrough technologies through acquisition requires novel competences and high coordination abilities, the lack of which can hinder innovation (Grigoriou and Rothaermel, 2017).

Research has shown that non-equity venturing alliances are more likely to be useful for explorative learning than joint ventures or acquisitions (Schildt et al., 2005). Interdivisional knowledge among diverse firms has a stronger impact on the quality of innovation than knowledge that exists within the boundaries of a single firm. This supports the hypothesis that the most diverse types of knowledge trigger the most radical forms of innovation (Miller et al., 2007).

The acquisition of unrelated knowledge is usually costlier and riskier because of the technological distance between the acquirer's and the target's knowledge domains. Low levels of absorptive capacity can further inhibit a firm's ability to transfer and integrate new unrelated knowledge. Conversely, firms with significant experience of M\&As and high levels of absorptive capacity can overcome technological distance and more efficiently support the knowledge recombination process, which, nevertheless, leads to sustain pre-existing technological trajectories, obeying to a specialization path. Despite the potential for radical innovation from the acquisition of companies owning unrelated knowledge, the case illustrates that even when the process of exploration of distant knowledge domains is available, the company prefers to use that knowledge to reinforce the technological specialization, creating products and technologies that conformed to its preexisting technological patterns. Hence, we propose the following proposition:

Proposition 2. Even if technological acquisitions enable companies to adopt a technological diversification trajectory through a recombination process that exploits complementary or unrelated knowledge from the target, the acquirer tends to use the acquired knowledge for reinforcing its specialization.

Paradoxically, the case informs that in case of development of unrelated knowledge, this was due to the exploitation of the collaboration with acquired companies specialized in related knowledge domains. This is the most interesting result of the study, which asks for further 
testing by scholars willing to deepen the "dark side" of open innovation, which, as our case illustrates, is not necessarily conducive to radical innovation.

Proposition 3. Radical innovations can derive from the close knowledge recombination, and not necessarily coming from the exploration of distant knowledge through acquisitions.

Overall, our analysis shows that L'Oréal's innovation strategy was strongly path dependent. L'Oréal did not use the open innovation approach to explore new knowledge domains. Rather, it engaged in repeated acquisitions to develop its existing technological trajectory through the realization of incremental innovations that have strengthened its technological specialization. This trajectory aligns with Hargadon's (2003) argument that innovators rarely come up with completely novel ideas; instead, they recombine old ideas into new ones, adapting them from one context to another. This is supported by the fact that in some cases, L'Oréal used similar knowledge acquired from the target to develop unrelated knowledge, which suggests that a high level of specialization is required for innovation in more distant domains. Since its first patent, for a hair dye formula containing a blend of harmless chemical compounds, which was filed on the 24th March 1908 by the company's founder, the French chemist Eugène Schueller, L'Oréal linked the company's growth with the development of the global "market of beauty." Its strong innovation strategy enabled the company to become the undisputed "queen" of the beauty industry.

Our empirical evidence shows that in large organizations, invention is still the result of a long accumulation process, predominantly based on the recombination of existing knowledge owned by the organization for new uses and applications. As Schoenmakers and Duysters (2010) emphasized, recombining existing knowledge can lead to very important innovations and sometimes to new knowledge related to an entirely new domain. An emblematic case is that of hair dyeing shampoo, which combines competences in shampoo production and hair dye production.

To sum up our evidence and open a discussion on the effects of technological acquisitions on the innovation trajectories of firms, we propose a taxonomy of knowledge recombination through acquisitions, shown in Figure 3.

Four innovation trajectories can be identified: (1) pure specialization, (2) recombinant specialization, (3) related diversification and (4) pure diversification. The first trajectory pertains to companies seeking to exploit their core competences and reinforce their competitive advantage as leaders in the market through the acquisition of companies with similar knowledge. The second is typical of companies that are engaged in innovative
Technological acquisitions paradox

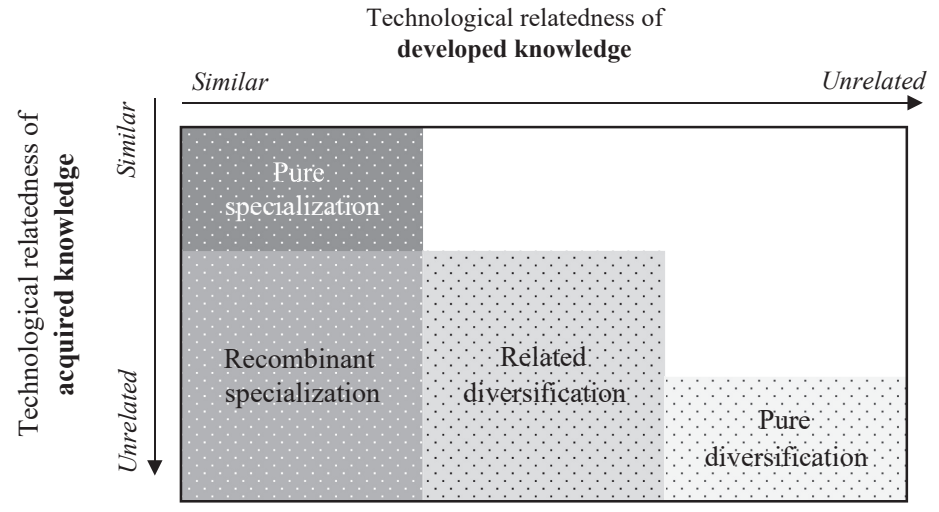

Figure 3. A proposed taxonomy of knowledge recombination through technological acquisitions 
EJIM

25,6

collaborations with partners and suppliers and that decide to vertically integrate members of their network to internalize complementary knowledge, thereby strengthening their core competences. The third concerns companies that search for complementary or unrelated knowledge to explore new trajectories in conjunction with a related diversification pattern. The last trajectory relates to companies that search far from their own domain of knowledge for unrelated knowledge and acquire companies that can enable them to explore new trajectories and develop technologies not considered in their past innovation strategies.

\section{Conclusions}

\subsection{Contribution}

This paper explores the impact of technological acquisitions on the knowledge recombination process involved in the innovation activity of L'Oréal, a leading firm in the beauty industry. We explored the extent to which the focal firm assimilated different types of knowledge throughout technological acquisitions; then, we investigated the extent to which the acquired knowledge contributed to the specialization or diversification of the company's technological trajectory. The most interesting evidence that emerged from our empirical analysis is presented below.

The most important result is that the role of an acquired external firm's knowledge in an acquisition is not particularly relevant in quantitative terms: only about 3\% of L'Oréal patents have cited a patent of an acquired company. This reveals how the process of invention and innovation at L'Oréal is prevalently based on a closed innovation model (Balconi et al., 2010), which is built on the ability to create and accumulate knowledge internally. While external knowledge sourcing plays a role in the company's innovation strategy, the classical process of closed innovation based on internal knowledge generation is more important (Grigoriou and Rothaermel, 2017; Manzini et al., 2017; Knott and Vieregger, 2020). Classifying the company's acquired knowledge in terms of similar, complementary, and unrelated knowledge, shows that the flows of knowledge coming from outside are mainly composed of similar and complementary knowledge. The acquisition of unrelated knowledge is a rare phenomenon in L'Oréal's history and has not led to a flow of radical innovations. Quantitatively, similar knowledge appears to be more important than complementary knowledge, although both have played a role, contributing to extending the depth more than the breadth of L'Oréal's patent portfolio.

\subsection{Theoretical implications}

We contribute to innovation management literature by offering evidence of a paradoxical use of external knowledge from technological acquisitions, being it close or far from the consolidated technological trajectory of the company. We observed, in fact, a persistent trend towards the strengthening of pre-existent technological specialization, providing evidence of a clear path-dependent innovation model, which is, nevertheless, successful in the beauty industry. Moreover, our findings suggest caution in claiming the primacy of the "new" open innovation model over the "old" closed innovation model. Not all successful firms base their innovation strategy on an open innovation model, and when they decide to combine closed and open innovation models, they might go for a marginal adoption of the latter. Indeed, in these cases knowledge recombination through acquisitions lead to sustain a path-dependent innovation process (Nerkar, 2003) rather than an exploration and innovation trajectory.

Consequently, we recommend caution when examining the innovation strategies of successful firms, which might base their competitive advantage on the ability to reinforce core competences, with limited recourse to external sourcing. It appears that a greater reflection is required on the relationship between the resource-based view (and the dynamic 
capabilities perspective), on the one hand, and the M\&A and collaboration perspective, on the other (Bogers et al., 2019). Further research might test the validity of our arguments in different companies and fields of specialization. The cases of Apple and Tesla seem to represent similar approaches to innovation and may be fruitful to investigate. We have proposed a taxonomy of knowledge recombination through acquisitions, which might guide future researchers in studying the possible output of an innovation strategy through acquisitions. Our results might find support in complementary empirical evidence arising from analyses of other firms in the beauty industry or in other industries.

\subsection{Managerial implications}

Our research also sheds light on the management of acquisitions, and on their role in supporting the growth of an innovative company. Managers should be able to use technological acquisitions as a tool to sustain the core competences of a firm through the absorption of related knowledge from a pool of selected partners. A broad sourcing strategy might not be the most remunerative. According to Laursen and Salter (2006), when the sources of knowledge for an innovation process exceed a certain level, coordination and knowledge recombination requires excessive effort.

Therefore, when considering an open innovation strategy, companies should consider the extent of their reliance on external knowledge sources, and compare this with a strategy of levering internal R\&D alongside an open innovation management.

\subsection{Limitations and further research}

We acknowledge that our research has certain limitations, mainly connected to our choice to study a single case, and to limit our analysis to few different types of knowledge. Nevertheless, we believe that evidence from a single case study can provide more fine-grained insights into the knowledge recombination processes compared to a more general study. This has also enabled us to isolate the innovation strategies at the firm level, obtaining some results that suggest an alternative approach to the open innovation model. Further research on different companies, or sectors, might enable us to apply our analytical framework to other contexts, testing the validity of our taxonomy.

\section{Notes}

1. All the information used in this research and concerning L'Oréal case study is publicly available.

2. At either the four- or seven-digit IPC level.

\section{References}

Ahuja, G. and Katila, R. (2001), "Technological acquisitions and the innovation performance of acquiring firms: a longitudinal study", Strategic Management Journal, Vol. 22 No. 3, pp. 197-220.

Alawamleh, M., Ismail, L.B., Aladwan, K. and Saleh, A. (2018), "The influence of open/closed innovation on employees' performance", International Journal of Organizational Analysis, Vol. 26 No. 1, pp. 75-90, doi: 10.1108/IJOA-08-2017-1207.

Antonelli, C., Krafft, J. and Quatraro, F. (2010), "Recombinant knowledge and growth: the case of ICTs", Structural Change and Economic Dynamics, Vol. 21 No. 1, pp. 50-69.

Apa, R., De Noni, I., Orsi, L. and Sedita, S.R. (2018), "Knowledge space oddity: how to increase the intensity and relevance of the technological progress of European regions", Research Policy, Vol. 47 No. 9, pp. 1700-1712.

Balconi, M., Brusoni, S. and Orsenigo, L. (2010), "In defence of the linear model: an essay", Research Policy, Vol. 39 No. 1, pp. 1-13.
Technological acquisitions paradox 
EJIM

25,6

Balland, P.A., Boschma, R., Crespo, J. and Rigby, D.L. (2019), "Smart specialization policy in the European Union: relatedness, knowledge complexity and regional diversification", Regional Studies, Vol. 53 No. 9, pp. 1252-1268.

Bauer, F. and Matzler, K. (2014), "Antecedents of M\&A success: the role of strategic complementarity, cultural fit, and degree and speed of integration", Strategic Management Journal, Vol. 35 No. 2, pp. 269-291.

Belussi, F., Sedita, S.R., Ganzaroli, A. and Orsi, L. (2016), "Evolving through innovation and knowledge reutilization: the case of L'Oréal", in Innovation, Alliances, and Networks in HighTech Environments, Routledge, Abingdon, pp. 319-354.

Bogers, M., Chesbrough, H., Heaton, S. and Teece, D.J. (2019), "Strategic management of open innovation: a dynamic capabilities perspective", California Management Review, Vol. 62 No. 1, pp. 77-94.

Boschma, R. (2017), "Relatedness as driver of regional diversification: a research agenda", Regional Studies, Vol. 51 No. 3, pp. 351-364.

Bresman, H., Birkinshaw, J. and Nobel, R. (1999), "Knowledge transfer in international acquisitions", Journal of International Business Studies, Vol. 30 No. 3, pp. 439-462.

Carnabuci, G. and Operti, E. (2013), "Where do firms' recombinant capabilities come from? Intraorganizational networks, knowledge, and firms' ability to innovate through technological recombination", Strategic Management Journal, Vol. 34 No. 13, pp. 1591-1613.

Cassiman, B. and Veugelers, R. (2006), "In search of complementarity in innovation strategy: internal R\&D and external knowledge acquisition", Management Science, Vol. 52 No. 1, pp. 68-82.

Castaldi, C., Frenken, K. and Los, B. (2015), "Related variety, unrelated variety and technological breakthroughs: an analysis of US state-level patenting", Regional Studies, Vol. 49 No. 5, pp. 767-781.

Chesbrough, H. (2003), Open Innovation: the New Imperative for Creating and Profiting from Technology, Harvard Business School Press, Boston.

Chiaroni, D., Chiesa, V. and Frattini, F. (2011), “The Open Innovation Journey: how firms dynamically implement the emerging innovation management paradigm”, Technovation, Vol. 31 No. 1, pp. 34-43.

Cloodt, M., Hagedoorn, J. and Van Kranenburg, H. (2006), "Mergers and acquisitions: their effect on the innovative performance of companies in high-tech industries", Research Policy, Vol. 35 No. 5, pp. 642-654.

Cohen, W.M. and Levinthal, D.A. (1990), "Absorptive capacity: a new perspective on learning and innovation”, Administrative Science Quarterly, Vol. 35 No. 1, pp. 128-152.

Colombo, M.G. and Rabbiosi, L. (2014), "Technological similarity, post-acquisition R\&D reorganization, and innovation performance in horizontal acquisitions", Research Policy, Vol. 43 No. 6, pp. 1039-1054.

Das, T.K. and Teng, B.S. (2000), "A resource-based theory of strategic alliances", Journal of Management, Vol. 26 No. 1, pp. 31-61.

Deng, P. (2010), "Absorptive capacity and a failed cross-border M\&A”, Management Research Review, Vol. 33 No. 7, pp. 673-682.

Doz, Y.L. (1996), "The evolution of cooperation in strategic alliances: initial conditions or learning processes?", Strategic Management Journal, Vol. 17 No. S1, pp. 55-83.

Dyer, J.H., Kale, P. and Singh, H. (2001), "How to make strategic alliances work", MIT Sloan Management Review, Vol. 42 No. 4, pp. 37-43.

Eisenhardt, K. (1989), “Building theories from case study research”, Academy of Management Review, Vol. 14, pp. 532-550.

Frenken, K., van Oort, F.G. and Verburg, T. (2007), "Related variety, unrelated variety and regional economic growth", Regional Studies, Vol. 41, pp. 685-697. 
Ganzaroli, A., De Noni, I., Orsi, L. and Belussi, F. (2016), "The combined effect of technological relatedness and knowledge utilization on explorative and exploitative invention performance post-M \& A", European Journal of Innovation Management, Vol. 19 No. 2, pp. 167-188.

Grant, R.M. and Baden-Fuller, C. (2004), "A knowledge accessing theory of strategic alliances”, Journal of Management Studies, Vol. 41 No. 1, pp. 61-84.

Grigoriou, K. and Rothaermel, F.T. (2017), "Organizing for knowledge generation: internal knowledge networks and the contingent effect of external knowledge sourcing", Strategic Management Journal, Vol. 38 No. 2, pp. 395-414.

Grillitsch, M., Asheim, B. and Trippl, M. (2018), "Unrelated knowledge combinations: the unexplored potential for regional industrial path development", Cambridge Journal of Regions, Economy and Society, Vol. 11 No. 2, pp. 257-274.

Grimpe, C. and Hussinger, K. (2014), "Resource complementarity and value capture in firm acquisitions: the role of intellectual property rights", Strategic Management Journal, Vol. 35 No. 12 , pp. 1762-1780.

Gruber, M., Harhoff, D. and Hoisl, K. (2013), "Knowledge recombination across technological boundaries: scientists vs. engineers", Management Science, Vol. 59 No. 4, pp. 837-851.

Gupta, A.K., Smith, K.G. and Shalley, C.E. (2006), "The interplay between exploration and exploitation”, Academy of Management Journal, Vol. 49 No. 4, pp. 693-706.

Hargadon, A. (2003), How Breakthroughs Happen: the Surprising Truth about How Companies Innovate, Harvard Business Press, Boston, Massachussets.

Hitt, M.A., Hoskisson, R.E., Johnson, R.A. and Moesel, D.D. (1996), “The market for corporate control and firm innovation”, Academy of Management Journal, Vol. 39 No. 5, pp. 1084-1119.

Hitt, M., Harrison, J., Ireland, R.D. and Best, A. (1998), "Attributes of successful and unsuccessful acquisitions of US firms", British Journal of Management, Vol. 9 No. 2, pp. 91-114.

Hung, S.W. and Tang, R.H. (2008), "Factors affecting the choice of technology acquisition mode: an empirical analysis of the electronic firms of Japan, Korea and Taiwan”, Technovation, Vol. 28 No. 9, pp. 551-563.

Jones, G. (2010), Beauty Imagined: A History of the Global Beauty Industry, Oxford University Press, Oxford.

Junni, P., Sarala, R.M., Tarba, S.Y. and Weber, Y. (2015), "The role of strategic agility in acquisitions", British Journal of Management, Vol. 26 No. 4, pp. 596-616.

Kang, K.H., Jo, G.S. and Kang, J. (2015), "External technology acquisition: a double-edged sword", Asian Journal of Technology Innovation, Vol. 23 No. 1, pp. 35-52.

Katila, R. and Ahuja, G. (2002), "Something old, something new: a longitudinal study of search behavior and new product introduction", Academy of Management Journal, Vol. 45 No. 6, pp. 1183-1194.

Kauffman, R.J., McAndrews, J. and Wang, Y.M. (2000), "Opening the 'black box' of network externalities in network adoption”, Information Systems Research, Vol. 11 No. 1, pp. 61-82.

Knott, A.M. and Vieregger, C. (2020), "Reconciling the firm size and innovation puzzle", Organization Science, Vol. 31 No. 2, pp. 477-488.

Kogut, B. and Zander, U. (1992), "Knowledge of the firm, combinative capabilities, and the replication of technology”, Organization Science, Vol. 3 No. 3, pp. 383-397.

Kumar, S., Massie, C. and Dumonceaux, M.D. (2006), "Comparative innovative business strategies of major players in cosmetic industry", Industrial Management and Data Systems, Vol. 106 No. 3, pp. 285-306, doi: 10.1108/02635570610653461.

Laursen, K. and Salter, A. (2006), "Open for innovation: the role of openness in explaining innovation performance among UK manufacturing firms", Strategic Management Journal, Vol. 27 No. 2, pp. 131-150.

Technological acquisitions paradox 
EJIM

25,6

Lavie, D., Stettner, U. and Tushman, M.L. (2010), "Exploration and exploitation within and across organizations", The Academy of Management Annals, Vol. 4 No. 1, pp. 109-155.

Lichtenthaler, U. (2009), "Absorptive capacity, environmental turbulence, and the complementarity of organizational learning processes", Academy of Management Journal, Vol. 52 No. 4, pp. 822-846.

Lin, B.W. and Wu, C.H. (2010), "How does knowledge depth moderate the performance of internal and external knowledge sourcing strategies?”, Technovation, Vol. 30 Nos 11-12, pp. 582-589.

Love, J.H. and Roper, S. (2009), "Organizing innovation: complementarities between cross-functional teams", Technovation, Vol. 29 No. 3, pp. 192-203.

Makri, M., Hitt, M.A. and Lane, P.J. (2010), “Complementary technologies, knowledge relatedness, and invention outcomes in high technology mergers and acquisitions", Strategic Management Journal, Vol. 31 No. 6, pp. 602-628.

Manzini, R., Lazzarotti, V. and Pellegrini, L. (2017), "How to remain as closed as possible in the open innovation era: the case of Lindt and Sprüngli”, Long Range Planning, Vol. 50 No. 2, pp. 260-281.

Mathison, S. (1988), “Why triangulate?”, Educational Research, Vol. 17 No. 2, pp. 13-17.

McCarthy, K.J. and Aalbers, H.L. (2016), "Technological acquisitions: the impact of geography on postacquisition innovative performance”, Research Policy, Vol. 45 No. 9, pp. 1818-1832.

Miller, D.J., Fern, M.J. and Cardinal, L.B. (2007), "The use of knowledge for technological innovation within diversified firms", Academy of Management Journal, Vol. 50 No. 2, pp. 307-325.

Mowery, D.C., Oxley, J.E. and Silverman, B.S. (1996), "Strategic alliances and interfirm knowledge transfer", Strategic Management Journal, Vol. 17 No. S2, pp. 77-91.

Nagle, F. and Teodoridis, F. (2020), "Jack of all trades and master of knowledge: the role of diversification in new distant knowledge integration”, Strategic Management Journal, Vol. 41 No. 1, pp. 55-85.

Nerkar, A. (2003), "Old is gold? The value of temporal exploration in the creation of new knowledge", Management Science, Vol. 49 No. 2, pp. 211-229.

Nooteboom, B., Van Haverbeke, W., Duysters, G., Gilsing, V. and Van den Oord, A. (2007), "Optimal cognitive distance and absorptive capacity", Research Policy, Vol. 36 No. 7, pp. 1016-1034.

Öberg, C. (2011), "Acquiring once, acquiring twice-lessons learned from repeated acquisitions of innovative firms", International Journal of Innovation Management, Vol. 15 No. 6, pp. 1243-1269.

Orsi, L., Ganzaroli, A., De Noni, I. and Marelli, F. (2015), "Knowledge utilisation drivers in technological M\&As", Technology Analysis and Strategic Management, Vol. 27 No. 8, pp. 877-894.

Patterson, W. and Ambrosini, V. (2015), "Configuring absorptive capacity as a key process for research intensive firms", Technovation, Vol. 36 No. 13, pp. 77-89.

Phelps, C.C. (2010), "A longitudinal study of the influence of alliance network structure and composition on firm exploratory innovation", Academy of Management Journal, Vol. 53 No. 4, pp. 890-913.

Phene, A., Fladmoe-Lindquist, K. and Marsh, L. (2006), "Breakthrough innovations in the US biotechnology industry: the effects of technological space and geographic origin", Strategic Management Journal, Vol. 27 No. 4, pp. 369-388.

Puranam, P. and Srikanth, K. (2007), "What they know vs. what they do: how acquirers leverage technology acquisitions", Strategic Management Journal, Vol. 28 No. 8, pp. 805-825.

Rosenkopf, L. and Almeida, P. (2003), "Overcoming local search through alliances and mobility", Management Science, Vol. 49 No. 6, pp. 751-766.

Rothaermel, F.T. and Alexandre, M.T. (2009), "Ambidexterity in technology sourcing: the moderating role of absorptive capacity”, Organization Science, Vol. 20 No. 4, pp. 759-780.

Rothaermel, F.T. and Boeker, W. (2008), "Old technology meets new technology: complementarities, similarities, and alliance formation”, Strategic Management Journal, Vol. 29 No. 1, pp. 47-77.

Schildt, H.A., Maula, M.V. and Keil, T. (2005), "Explorative and exploitative learning from external corporate ventures", Entrepreneurship Theory and Practice, Vol. 29 No. 4, pp. 493-515. 
Schoenmakers, W. and Duysters, G. (2010), "The technological origins of radical inventions”, Research Policy, Vol. 39 No. 8, pp. 1051-1059.

Schumpeter, J.A. (1911), Theorie der wirtschaftlichen Entwicklung, Duncker \& Humbolt, Leipzig.

Sears, J. and Hoetker, G. (2014), "Technological overlap, technological capabilities, and resource recombination in technological acquisitions", Strategic Management Journal, Vol. 35 No. 1, pp. $48-67$.

Siggelkow, N. (2007), "Persuasion with case studies", Academy of Management Journal, Vol. 50 No. 1, pp. 20-24.

Todorova, G. and Durisin, B. (2007), “Absorptive capacity: valuing a reconceptualization”, Academy of Management Review, Vol. 32 No. 3, pp. 774-786.

Tsai, J.M., Chang, C.C. and Hung, S.W. (2018), "Technology acquisition models for fast followers in high-technological markets: an empirical analysis of the LED industry", Technology Analysis and Strategic Management, Vol. 30 No. 2, pp. 198-210.

Uhlenbruck, K., Hitt, M.A. and Semadeni, M. (2006), "Market value effects of acquisitions involving Internet firms: a resource-based analysis", Strategic Management Journal, Vol. 27 No. 10, pp. 899-913.

Vasudeva, G. and Anand, J. (2011), "Unpacking absorptive capacity: a study of knowledge utilization from alliance portfolios", Academy of Management Journal, Vol. 54 No. 3, pp. 611-623.

Verhoeven, D., Bakker, J. and Veugelers, R. (2016), "Measuring technological novelty with patentbased indicators", Research Policy, Vol. 45 No. 3, pp. 707-723.

Vermeulen, F. and Barkema, H. (2001), "Learning through acquisitions", Academy of Management Journal, Vol. 44 No. 3, pp. 457-476.

Yin, R. (1981), "The case study crisis: some answers", Administrative Science Quarterly, Vol. 26, pp. 58-65.

Yin, R.K. (2003), Case Study Research: Design and Methods, 3rd ed., Sage, Thousand Oaks.

Yin, R. (2014), Case Study Research Design and Methods, 5th ed., Sage, Newbury Park.

Zaheer, A., Castañer, X. and Souder, D. (2013), "Synergy sources, target autonomy, and integration in acquisitions", Journal of Management, Vol. 39 No. 3, pp. 604-632.

Zahra, S.A. and George, G. (2002), "Absorptive capacity: a review, reconceptualization, and extension”, Academy of Management Review, Vol. 27 No. 2, pp. 185-203.

Ziedonis, R.H. (2004), "Don't fence me in: fragmented markets for technology and the patent acquisition strategies of firms", Management Science, Vol. 50 No. 6, pp. 804-820.

\section{Further reading}

Chesbrough, H. and Prencipe, A. (2008), "Networks of innovation and modularity: a dynamic perspective", International Journal of Technology Management, Vol. 42 No. 4, pp. 414-425.

Feldman, M.P. (1994), "Knowledge complementarity and innovation", Small Business Economics, Vol. 6 No. 5, pp. 363-372.

Robertson, P.L. and Langlois, R.N. (1995), "Innovation, networks, and vertical integration”, Research Policy, Vol. 24 No. 4, pp. 543-562.

Rosenkopf, L. and Nerkar, A. (2001), "Beyond local search: boundary-spanning, exploration, and impact in the optical disk industry", Strategic Management Journal, Vol. 22 No. 4, pp. 287-306.

Sexton, J.C. (2015), “Acquisitions as an instrument of organizational adaptation through innovation", in The Routledge Companion to Mergers and Acquisitions, pp. 35-50.

Weitzman, M.L. (1998), "Recombinant growth”, Quarterly Journal of Economics, Vol. 113, pp. 331-360.

Technological acquisitions paradox 
EJIM

25,6

\section{About the authors}

Silvia Rita Sedita is an Associate Professor of Management at the Department of Economics and Management, University of Padova, Italy. She holds a PhD in Economics and Management of Firms and Local Systems at the University of Florence. Main research interest is the management of innovation in inter-organizational networks, industrial districts and clusters. She has published book chapters and articles in journals such as Research Policy, Industry and Innovation, Technology Analysis and Strategic Management, Regional Studies, Journal of Economic Geography, International Journal of Project Management, European Planning Studies, R\&D Management. Silvia Rita Sedita is the corresponding author and can be contacted at: silvia.sedita@unipd.it

Fiorenza Belussi is a Full Professor of Management at the Department of Economics and Management, University of Padova, Italy. She obtained her PhD in 1993, from SPRU, Science Policy Research Unit (University of Sussex, United Kingdom). Her areas of interest include management of innovation and creativity (creative industries, theoretical models on innovation diffusion through gatekeepers, open innovation and local systems of innovation) as well as international business and the impact of globalization on local economies. She has participated at several international projects and has published many articles in international journals, such as Research Policy, Cambridge Journal of Economics, Regional Studies, European Planning Studies, Industry and Innovation.

Ivan De Noni is a Senior Researcher at the Department of Economics and Management, University of Padova, Italy, where he teaches business and innovation management as well as marketing and digital media management. He graduated in Economics and International Finance at the University of Milan and holds a Ph.D in Management and Corporate Finance Macroeconomics and Economics of Human Capital. His research has been published in journals such as Research Policy, Technological Forecasting and Social Change, European Journal of Innovation Management, Technology Analysis and Strategic Management.

Roberta Apa is a Adjunct Professor at the University of Milan, Italy. She holds a doctorate in Management from the University of Milan. Her main research fields are innovation processes of startups and small and medium enterprises, business incubators and entrepreneurial development. Her research has been published in journals such as Research Policy, International Journal of Project Management, R\&D Management, Journal of International Entrepreneurship and Review of Integrative Business and Economics Research. She has also contributed to several book chapters.

For instructions on how to order reprints of this article, please visit our website:

www.emeraldgrouppublishing.com/licensing/reprints.htm

Or contact us for further details: permissions@emeraldinsight.com 